\title{
Minimizing confounders and increasing data quality in murine models for studies of the gut microbiome
}

Jun Miyoshi $^{1}$, Vanessa Leone ${ }^{1}$, Kentaro Nobutani ${ }^{1}$, Mark W Musch ${ }^{1}$ ， Kristina Martinez-Guryn ${ }^{1,2}$, Yunwei Wang $^{1}{ }^{\text {, Sawako Miyoshi }}{ }^{1}$, Alexandria M Bobe ${ }^{1}$, A. Murat Eren ${ }^{1}$, Eugene B Chang ${ }^{\text {Corresp. } 1}$

1 Department of Medicine, The University of Chicago, Chicago, Illinois, United States

2 Biomedical Sciences Program, Midwestern University, Downers Grove, Illinois, United States

Corresponding Author: Eugene B Chang

Email address: echang@medicine.bsd.uchicago.edu

Murine models are widely used to explore host-microbe interactions because of the challenges and limitations inherent to human studies. However, microbiome studies in murine models are not without their nuances. Inter-individual variations in gut microbiota are frequent even in animals housed within the same room. We therefore sought to find an efficient and effective standard operating procedure (SOP) to minimize these effects to improve consistency and reproducibility in murine microbiota studies. Mice were housed in a single room under specific-pathogen free conditions. Soiled cage bedding was routinely mixed weekly and distributed among all cages from weaning ( 3 weeks old) until the onset of the study. Females and males were separated by sex and group-housed (up to 5 mice/ cage) at weaning. 16S rRNA gene analyses of fecal samples showed that this protocol significantly reduced pre-study variability of gut microbiota amongst animals compared to other conventional measures used to normalize microbiota when large experimental cohorts have been required. A significant and consistent effect size was observed in gut microbiota when mice were switched from regular chow to purified diet in both sexes. However, sex and aging appeared to be independent drivers of gut microbial assemblage and should be taken into account in studies of this nature. In summary, we report a practical and effective pre-study SOP for normalizing the gut microbiome of murine cohorts that minimizes inter-individual variability and resolves co-housing problems inherent to male mice. This SOP may increase quality, rigor, and reproducibility of data acquisition and analysis. 
1 Minimizing confounders and increasing data quality in murine models for studies of the gut 2 microbiome

3

4 Authors

5 Jun Miyoshi $^{1}$, Vanessa Leone ${ }^{1}$, Kentaro Nobutani ${ }^{1}$, Mark W. Musch ${ }^{1}$, Kristina Martinez-Guryn ${ }^{1}$,

$6{ }^{2}$, Yunwei Wang ${ }^{1}$, Sawako Miyoshi ${ }^{1}$, Alexandria M. Bobe ${ }^{1}$, A. Murat Eren ${ }^{1}$ and Eugene B.

7 Chang ${ }^{1 *}$

8

9 Affiliations

10 1) Department of Medicine, Knapp Center for Biomedical Discovery, Knapp Center for 11 Biomedical Discovery, Rm 9130, the University of Chicago

12900 E 57th St. Chicago, IL, USA 60637

13 2) Biomedical Sciences Program, Midwestern University

14 Science Hall 203D, 555 31st St. Downers Grove, IL, USA 60515

15

16 Corresponding author

17 Eugene B. Chang, M.D.

18 Email: echang@medicine.bsd.uchicago.edu 


\section{Abstract}

Murine models are widely used to explore host-microbe interactions because of the challenges and limitations inherent to human studies. However, microbiome studies in murine models are not without their nuances. Inter-individual variations in gut microbiota are frequent even in animals housed within the same room. We therefore sought to find an efficient and effective standard operating procedure (SOP) to minimize these effects to improve consistency and reproducibility in murine microbiota studies. Mice were housed in a single room under specific-pathogen free conditions. Soiled cage bedding was routinely mixed weekly and distributed among all cages from weaning ( 3 weeks old) until the onset of the study. Females and males were separated by sex and group-housed (up to 5 mice/ cage) at weaning. 16S rRNA gene analyses of fecal samples showed that this protocol significantly reduced pre-study variability of gut microbiota amongst animals compared to other conventional measures used to normalize microbiota when large experimental cohorts have been required. A significant and consistent effect size was observed in gut microbiota when mice were switched from regular chow to purified diet in both sexes. However, sex and aging appeared to be independent drivers of gut microbial assemblage and should be taken into account in studies of this nature. In summary, we report a practical and effective pre-study SOP for normalizing the gut microbiome of murine cohorts that minimizes inter-individual variability and resolves co-housing problems inherent to male mice. This SOP may increase quality, rigor, and reproducibility of data acquisition and analysis.

\section{Introduction}

The involvement of the gut microbiota in human diseases is under extensive investigation and has been boosted by recent advances in cultivation-independent bioinformatic approaches to study complex microbial communities. Reduced cost and increased access to 16S rRNA gene amplicon sequencing and metagenomic analysis to examine the bacterial community composition and function of the gut microbiota have improved our understanding of the role of gut microbiota in health and disease. Epidemiological studies using these methodologies have presented the association of gut dysbiosis with various diseases ranging from intestinal diseases to extraintestinal and systemic diseases (Carding et al. 2015; Shreiner et al. 2015). Despite these advances, a large variation of microbiota has been observed between human subjects (Faith et al. 2013; Lozupone et al. 2012; Turnbaugh et al. 2009a; Yatsunenko et al. 2012). Human microbiota can be 
affected by factors, such as environment (Yatsunenko et al. 2012), diet (David et al. 2014; Kashtanova et al. 2016; Wu et al. 2011), sex (Haro et al. 2016) and age (O'Toole and Jeffery 2015; Saraswati and Sitaraman 2014). The resulting large interindividual variability in microbiota coupled with genetic diversity are confounding factors that are challenging to overcome when studying host-microbe interactions in humans. In contrast, many of these variables can be controlled when murine models are used in the study of the gut microbiota. While inherent differences between human and mouse are indeed limiting factors, a properly controlled murine study can provide important insights into host-microbe relationships which can help establish causality, disease pathogenesis, and interventional strategies. As in humans, the murine microbiota is influenced by various factors. In mice, these include breeding environment (facilities and rooms) (Ericsson et al. 2015; Hufeldt et al. 2010; Rogers et al. 2014), genetic backgrounds (strains) (Org et al. 2016; Org et al. 2015), diet (Liu et al. 2012; Turnbaugh et al. 2009b), sex (Markle et al. 2013; Org et al. 2016) and age (Langille et al. 2014; Schloss et al. 2012). Furthermore, even in one specific room within a specific pathogen-free (SPF) animal vivarium, variation between cages can be observed, a phenomenon called "cage effect" (Hildebrand et al. 2013; McCafferty et al. 2013; Hoy et al. 2015). In studies with large cohorts of mice that consist of multiple cages per group, cage effects can lead to a large variability in gut microbiomes among animals within a study. This variability at experimental onset immediately introduces artifacts into studies of the gut microbiota, which can mask and skew experimental findings related to metabolism (Murphy et al. 2010), the immune system (Ivanov et al. 2008; Moon et al. 2015) or disease activity (Devkota et al. 2012; Markle et al. 2013).

Several strategies have been used to decrease inter-individual variability of the gut microbiota. Co-housing approaches are used to enable transfer of microbiota through shared environment and coprophagia, however, this is limited by the number of animals that can be housed in a single cage (McCafferty et al. 2013). Often, to achieve the numbers of mice for meaningful statistical analyses and reproducibility, age-matched rather than littermate mice are used which are divided among treatments or cages. This practice reintroduces cage effects and other variables that impact starting microbiota. Oral gavage of microbiota has also been used to conventionalize and normalize germfree and SPF mice with target microbial communities, however, this labor-intensive procedure induces stress and can cause injury or fatality even when performed by experienced personnel (Arantes-Rodrigues et al. 2012). For murine microbiota studies requiring multiple groups with a 
81 large number of animals, two simple measures have been used to prepare age-matched animals, including: (1) setting up multiple breeding pairs within a specific vivarium room where environment, cage changes, and dietary schedules are more uniform. Pups from different breeding pairs are then combined and used as a single group, and (2) a one-time purchase of mice from a vendor, followed by acclimation in a specific vivarium room several weeks in advance of an intended study. Additional limitations of these current practices, including aggressive behavior in adult males when cohoused, variation in the gut microbiota of different breeding pairs, known generational drift in microbiota (Choo et al. 2017), and differences between batches of mice purchased from a vendor, can have profound effects on microbial membership and function that affect experimental outcomes.

Despite these attempts to normalize gut microbes, we have observed appreciable differences in starting gut microbiota. Indeed, in our own hands, we have encountered difficulty in reproducing clear microbiome data in murine studies due, in part, to large variability among mice at the study onset. Therefore, an unmet need is the development of a simple and effective standard operational procedure (SOP) to minimize the individual variability and cage differences of microbiota among mice at the onset of a study. The SOP should provide optimal conditions so that true effects of a specific treatment on the gut microbiota can be observed. At the same time, the approach should be applicable to studies where large numbers of mice and cages are required to sufficiently power a study and ensure reproducibility (Moore and Stanley 2016). Considering these facts, we developed and vetted a "bedding transfer" procedure, where soiled bedding is mixed and distributed equally among pups at weaning (3 weeks of age) until the start of a particular study (e.g. 6-12 weeks of age) among multiple cages of mice. This approach was contrasted with two conventional procedures used to minimize variability as described above, namely, in-house breeding without bedding transfer or mass animal purchase from a vendor followed by acclimatization. We hypothesized that since soiled bedding contains microbiota both from the feces and the cage environment, the bedding transfer SOP amongst multiple cages would reduce the variability of the gut microbiota among a large number of mice due to coprophagia. To test this hypothesis, the effect of this SOP on fecal microbiota variability was compared to the effects of the two conventional procedures using 16S rRNA gene amplicon sequencing and analysis. In addition, the impacts of possible confounding factors including time, diet, sex, and age on fecal microbiota using this SOP were assessed. 


\section{Materials and Methods}

114 Animal

115 This study protocol was approved by the University of Chicago Animal Care and Use 116 Committee (protocols 71084 and 72101). C57Bl/6J mice were originally purchased from Jackson 117 Laboratory (Bar Harbor, ME, USA). We prepared three cohorts for this study. For cohort 1 and 118 cohort 2, mice were bred and raised at the University of Chicago Specific-Pathogen Free (SPF) 119 Animal Vivarium. For cohort 3, all mice were purchased from Jackson Laboratory at the same time and acclimated within our SPF animal vivarium for 2 weeks. Mice were fed Teklad Global 18\% Protein Rodent Diet (2018) (Envigo, WI, USA) (Institutional Animal Care and Use Committee (IACUC) protocol 71084). Cohort 1 was switched to AIN-76A Purified Diet (The American Institute of Nutrition. 1977) (Envigo, WI, USA) (IACUC protocol 72101) between 6 and 12 weeks of age. Mice in cohorts 2 and 3 were not switched to AIN-76A and used for separate purposes after analyzing the base line gut microbiota at the onset of each study. To reduce batch effect of the diet lot, we purchased AIN-76A as one single which was used throughout the experiment. Teklad Global 18\% Protein Rodent Diet (2018) was purchased by the University of Chicago Animal Resource Center, which distributes this diet to all vivarium rooms throughout the animal facility. Therefore, the variations between batches of Teklad Global 18\% Protein Rodent Diet (2018) cannot be strictly excluded.

\section{Bedding transfer}

Bedding transfers were performed among 14 female cages and 20 male cages (1-5 mice/ cage) in cohort 1. In our animal vivarium, fresh bedding is provided every 14 days by the animal husbandry staff. Bedding was mixed at 3-4 days and at 8-10 days following these cage changes, i.e. bedding transfers were performed twice within the two-week cycle. At each of these time points, roughly one-quarter of soiled bedding was collected from each cage and the bedding from all cages was mixed in an autoclaved sterile container, followed by redistribution across all cages. Soiled bedding was collected and mixed within a freshly cleaned biological safety cabinet (BSC) within the room where animals were housed. Standard barrier practices for BSC contamination include spraying down the hood with Clidox ${ }^{\circledR}$ and allowing it to sit for $\sim 3$ minutes prior to turning it on, followed by wipe-down with clean paper towels. In addition to appropriate personal 
143 protective equipment (disposable gown, hair bonnet, and face mask), researchers also donned clean 144 latex gloves and plastic tyvex sleeves. Only 3 personnel were involved in this SOP. Bedding transfer began at weaning and continued until the onset of fecal sample collections.

\section{Fecal samples}

Fresh stool pellets were harvested from animals at designated time points. For chronological analysis in cohort 1, all fecal samples were harvested at 6 am (time of lights on) throughout the study to avoid confounders of gut microbiota diurnal variation (Leone et al. 2015). Fecal samples were harvested 1 week after the cage changes throughout the experimental protocol and samples were kept frozen at $-80^{\circ} \mathrm{C}$ until DNA extraction.

\section{DNA extraction and $16 S$ rRNA gene sequencing analysis}

DNA was extracted from fecal samples using standard, published protocols (Wang et al. 2009). Sequences were obtained by MiSeq at the Next Generation Sequencing Core in the Biosciences Division at Argonne National Laboratory, amplifying the V4 region with standard protocols (Earth Microbiome Project. 2016). DNA sequences were analyzed by Quantitative Insights into Microbial Ecology (QIIME) version 1.9.1 (Caporaso et al. 2010), joining forward and reverse reads. Samples with less than 3000 sequences were excluded from the analyses. Operational taxonomic units (OTUs) were picked at 97\% sequence identity using the GreenGenes Database (The GreenGenes Database. 2013).

\section{Statistical analysis}

Analysis of similarities (ANOSIM) was performed using QIIME to examine the difference between cohorts and the impact of sex on fecal microbiota. Given that the same mice were analyzed at multiple time points, and to control for these effects, ADONIS with strata argument was performed using R, "vegan" package to assess the influence of diet and age. The number of permutations was 10000 or the maximum number of permutations allowed by the data. Permutation test with 10000 permutations was performed using $\mathrm{R}$ to compare the UniFrac distances of animals between cohorts. $p<0.05$ was considered statistically significant.

\section{Accession numbers}


174 The accession numbers for the mouse sample information and the microbial dataset reported in

175 this paper are BioProject: PRJNA397441 and SRA: SRP115420, respectively.

176

177

178

179

180

181

182

183

\section{Results}

Bedding transfer reduces the variability of fecal microbiota between groups of mice

To examine if the bedding transfer protocol could reduce fecal microbiota variability in $16 \mathrm{~S}$ rRNA amplicon sequencing analysis, 3 cohorts of C57Bl/6 wild-type mice were used (outlined in Figure 1). Each cohort was maintained in a separate room in our animal vivarium under SPF conditions. For cohort 1, 5 breeding pairs were obtained from an in-house bred mouse colony and maintained in one vivarium room ( $\mathrm{F}_{0}$ generation). Male and female mice were siblings, and their progeny ( $F_{1}$ generation) were used to set up 25 breeding pairs. Mice from the $F_{2}$ generation (57 females and 57 males) were exposed to bedding transfer (Figure 1A). For cohort 2, 19 male mice from 2 separate in-house breeding colonies (12 and 7, respectively) were maintained in a separate SPF room and were analyzed as a single group (Figure 1B). For cohort 3, 36 male mice were purchased from Jackson Laboratory (Bar Harbor, ME, USA) and acclimated in individual cages in a third SPF room for 2 weeks (Figure 1C). Animals in all cohorts were fed Teklad Global 18\% Protein Rodent Diet (2018) (Envigo, WI, USA) and were 6-12 weeks of age at the time of analyses. Cohort 1 males were compared to those in cohorts 2 and 3, respectively (Figure 2). PCoA plots for cohorts 1 and 2 are presented in Figure 2A, where unweighted UniFrac distances describe the OTUs existing in samples, while weighted UniFrac distances take into account the proportions of those OTUs. Permutation test for both unweighted and weighted UniFrac distances showed that the within-group distances of mice in cohort 1 were significantly decreased as compared to mice in cohort 2 ( $p=0.0001$ and 0.0001 in unweighted and weighted UniFrac distances, respectively; Figure 2B). ANOSIM showed significant differences in fecal microbiota between cohorts 1 and 2 ( $p=0.001$ and $\mathrm{R}=0.778$ in unweighted UniFrac distances, $p=0.001$ and $\mathrm{R}=0.655$ in weighted UniFrac distances). A comparison of unweighted and weighted UniFrac distances of cohorts 1 and 3 also revealed significant decreases of within-group Unifrac distances (each $p=0.0001$; Figure 2D) in cohort 1 as compared to cohort 3. ANOSIM showed significant differences in fecal microbiota between cohorts 1 and 3 ( $p=0.001$ and $\mathrm{R}=0.989$ in unweighted UniFrac distances, $p$ $=0.001$ and $\mathrm{R}=0.960$ in weighted UniFrac distances; Figure 2C). The bacterial community memberships based on 16S rRNA sequencing at both the phylum and genus levels in each cohort 
205

206

207

208

209

210

211

212

213

214

215

216

217

218

219

220

221

222

223

224

225

226

227

228

229

230

231

232

233

234

235

are shown in Figure S1. The comparisons of microbial community membership between cohorts housed in separate rooms within a vivarium by itself can lead to differences in gut microbiota that could be potential confounders. Daily health check monitoring by the animal husbandry staff and our own weekly health assessment of each mouse revealed no apparent and observable adverse events, such as ruffled fur appearance, decreased activity, injury due to fighting, or alopecia. These animal welfare concerns are in particular a limitation for co-housing male mice from different litters, which is avoided using this SOP. Together, these findings show that our SOP minimizes variance among animals without adverse co-housing effects when a large study cohort obtained from several breeding pairs is required. To examine how this SOP impacted downstream experimental procedures, we focused all subsequent analyses on cohort 1.

Normalization of starting gut microbiota results in a reproducible impact of diet on murine fecal microbiota community membership

The 57 female and 57 male mice in cohort 1 were weaned and maintained on Teklad Global 18\% Protein Rodent Diet throughout the bedding transfer SOP and baseline fecal samples were collected. Bedding transfer was stopped, and mice were switched to a defined AIN-76A Purified Diet formulation (The American Institute of Nutrition. 1977) (Envigo, WI, USA). One week after starting AIN-76A, fecal samples were harvested and DNA was extracted and compared with the baseline samples. We compared 16S rRNA gene amplicon sequencing separately for females and males. Fifty-six female and 56 male samples from the first harvest and 51 female and 57 male samples from the second harvest were plotted in PCoA plots (Figure 3, samples with less than 3000 reads were dropped from the analysis). PCoA analysis revealed both female and male samples exhibited significant shifts of microbiota in both unweighted and weighted UniFrac distances with ADONIS ( $p=0.0001$ and $\mathrm{R}^{2}=0.157$ in female unweighted UniFrac distances, $p=$ 0.0001 and $\mathrm{R}^{2}=0.405$ in female weighted UniFrac distances, $p=0.0001$ and $\mathrm{R}^{2}=0.158$ in male unweighted UniFrac distances, $p=0.0001$ and $\mathrm{R}^{2}=0.399$ in male weighted UniFrac distances). This data reveals that diet switch from Global 18\% Protein Diet to AIN-76A altered the fecal microbiota dramatically in both sexes in one week. The bacterial community membership based on 16S rRNA gene amplicon sequencing at both the phylum and genus levels of female and male animals fed each diet are shown in Figure S2. 
236

237

238

239

240

241

242

243

244

245

246

247

248

249

250

251

252

253

254

255

256

257

258

259

260

261

262

263

264

265

266

Sex differences in fecal microbiota are evident despite bedding transfer amongst sexes

Eight female and 8 male mice in cohort 1 were continued on the AIN-76A diet for an additional 24 weeks after the initial analysis to examine the influence of switching diet described above. At week 0 (the initial analysis), the mice were 7-10 weeks old and fecal samples were analyzed at week 12 and week 24. PCoA plots of unweighted and weighted UniFrac distances at weeks 0, 12 and 24 are shown in Figure 4A-C. At all time-points, ANOSIM showed a significant difference between female and male fecal 16S-rRNA-based community structure (Week $0: p=0.001$ and $\mathrm{R}$ $=0.432$ in unweighted UniFrac distances and $p=0.001$ and $\mathrm{R}=0.397$ in weighted UniFrac distances; Week 12: $p=0.001$ and $\mathrm{R}=0.465$ in unweighted UniFrac distances and $p=0.004$ and $\mathrm{R}=0.277$ in weighted UniFrac distances; Week 24: $p=0.003$ and $\mathrm{R}=0.695$ in unweighted UniFrac distances and $p=0.008$ and $\mathrm{R}=0.319$ in weighted UniFrac distances). These results indicate that there was a persistent sex difference in fecal microbiota despite the bedding transfer protocol. However, we did observe several common core OTUs in both sexes. The bacterial community membership at both the phylum and genus levels of female and male animals at weeks 0, 12 and 24 are shown in Figure S3.

\section{Aging elicits a large impact on fecal microbiota community membership regardless of sex}

The 8 females and 8 males were also analyzed to investigate the effect of aging on the fecal microbiota. PCoA plots of unweighted and weighted Unifrac distances with samples at weeks 0 , 12 and 24 are shown in Figure 5. ADONIS demonstrated that there were shifts in gut microbial community membership associated with aging in both sexes $\left(p=0.0001\right.$ and $\mathrm{R}^{2}=0.189$ in female unweighted UniFrac distances, $p=0.0001$ and $\mathrm{R}^{2}=0.362$ in female weighted UniFrac distances, $p=0.001$ and $\mathrm{R}^{2}=0.142$ in male unweighted UniFrac distances, $p=0.0004$ and $\mathrm{R}^{2}=0.396$ in male weighted UniFrac distances). ADONIS was also performed to assess $\mathrm{R}^{2}$ values in comparisons between weeks 0 vs. 12 and weeks 12 vs. 24 . The higher $\mathrm{R}^{2}$ is interpreted as the greater amount of variance among the observations explained by the time point difference. The test suggested that the aging effect was most evident in the first 12 weeks in males (Weeks 0 vs. 12: $\mathrm{R}^{2}=0.125$ in unweighted UniFrac distances and $\mathrm{R}^{2}=0.418$ in weighted UniFrac distances; Weeks 12 vs. 24: $\mathrm{R}^{2}=0.0676$ in unweighted UniFrac distances and $\mathrm{R}^{2}=0.0749$ in weighted UniFrac distances) while the aging effect was evident in both the first and later 12 weeks in females (Weeks 0 vs. 12: $\mathrm{R}^{2}=0.134$ in unweighted UniFrac distances and $\mathrm{R}^{2}=0.202$ in weighted UniFrac 
267 distances; Weeks 12 vs. 24: $\mathrm{R}^{2}=0.132$ in unweighted UniFrac distances and $\mathrm{R}^{2}=0.303$ in weighted 268 UniFrac distances).

\section{Discussion}

Murine models are commonly used to study host-microbe-environmental interactions and many investigators assume there is uniformity of gut microbiomes within groups and cages of mice prior to an experiment. Unfortunately, this is often not the case and even in studies conducted in a single room (environment), large variations in gut microbiota exist between cages that can significantly affect reproducibility and skew experimental results. These differences can arise from multiple factors, including genetic background, diet, sex, and age (Hoy et al. 2015). Controlling these variables to insure that the starting microbiota is uniform among paired experimental groups is therefore essential to improve rigor and reproducibility, which are now mandated by federal and non-federal funding agencies (NIH). Furthermore, this effort can contribute to the concept of the 3Rs (Replacement, Reduction, and Refinement), which is crucial from an ethical and scientific viewpoint and is now globally considered in animal studies. Other considerations prior to initiating studies of the gut microbiome include the development of an effective and practical study design, the necessity of starting with sufficiently large cohorts if time-series tissue harvests are envisioned, and the sufficient statistical power for reliable data analysis. To address this, we established a noninvasive bedding transfer SOP that promotes uniformity of gut microbiota across cages and this SOP also considers commonly used procedures to minimize confounding factors across cohorts as well as normalized microbiota prior to experiments. These involve: (1) using a single genetically identical strain, (2) housing all animals in one specific room (to control environment), (3) using the same diet for all mouse groups, (4) controlling for the effects of aging by utilizing age-matched mice, and (5) separating sexes and performing these analyses separately. Despite these measures, significant differences in gut microbiota along with generational drift are observed. While littermate cohorts are desirable, many studies require a large number of mice at the start to account for attrition in study cohorts as animals are harvested in sufficient numbers to adequately power the data at each time point. Here, investigators have to either combine different breeding colonies or acclimate age-matched mice purchased from a single vendor to achieve these numbers before the initiation of experiments. The logistics of achieving these pre-experimental conditions can be 
298

groups and cages. We now report a practical and effective bedding transfer protocol that addresses these problems, reducing many of the variabilities in gut microbiota among animals in large cohort studies of the gut microbiome. However, we concede that the present study design has a limitation to assess the efficacy of bedding transfer SOP because a strict control group without the SOP was not included. We also note that host factors, such as sex and aging are independent determinants of microbial assemblage, which must be factored into all studies of this nature. With regard to the former, this SOP can be applied safely even to co-housed adult male mice across multiple cages, completely avoiding territorial problems such as fighting and injury. Importantly, clear shifts in gut microbial communities in response to the transition from mouse chow to a purified diet is an excellent example of how a strong effect size can be seen across the different groups.

Differences in bacterial community membership were observed between cohorts 1-3 housed in separate rooms. We speculated two potential reasons for the observed "room effect." First, subtle differences in room environments (temperature, staff handlers, ventilation, etc.) can impact the assemblage of gut microbial communities among mice housed. Another possibility is that genetic drift among the $\mathrm{C} 57 \mathrm{Bl} / 6 \mathrm{~J}$ mice used for breeding in different rooms (either in-house or within a vendor's facility) could influence microbiota community membership. Regardless of the observed differences in gut microbiota of mice housed in different rooms, our conclusions are not altered and show that our SOP is effective and practical. With regard to 16S rRNA amplicon data analysis, we recognize the OTU-based methodology that Quantitative Insights into Microbial Ecology (QIIME) (Caporaso et al. 2010) employs has a limitation, including the reference databases (Schloss and Westcott 2011). The limitation of databases is most apparent in the assignment of taxonomy, which does not provide sufficient resolution beyond the genus level and therefore cannot rule out subtle changes in gut microbiota at the species or strain level. Furthermore, the 16S rRNA amplicon analysis only provides information on community membership and is unable to provide insights into community function and the impact elicited by diet, sex, and aging. Further analysis using shotgun metagenomics, metatranscriptomics, metabolomics and metaproteomics would be needed to address these issues which is beyond the scope of this study.

In regard to the impact of diet, both female and male mice showed a dramatic change in microbiota community membership after only one week following diet switch, which has also been observed by others in mice (Liu et al. 2012; Turnbaugh et al. 2009b). This phenomenon of rapid changes of gut microbiota induced by diet has also been reported in humans (David et al. 
329

330

331

332

333

334

335

336

337

338

339

340

341

342

343

344

345

346

347

348

349

350

351

352

353

354

355

356

357

358

359

2014). Together, these findings underscore that diet is an important determinant of gut microbial assemblage even for short-term studies. In this regard, each dietary component has to be carefully considered, as well as the source of each nutrient used for diet preparation. It cannot be assumed, for instance, that all dietary fats are the same. Teklad Global 18\% Protein Rodent Diet contains soybean oil whereas AIN-76A Purified Diet contains corn oil in different percentages; similarly, the fiber component is also dramatically different between these two diets. Even more subtle differences in diet (i.e. micronutrient content) can dramatically impact the gut microbiota.

We noted strong sex differences among the groups even after the mixed bedding protocol was instituted, suggesting that sex is a strong independent host factor driving gut microbial assemblage. This finding emphasizes the importance of analyzing both female and male animals separately in all gut microbiome studies, as these differences could cause differential effects in the host, e.g. the development of the immune system (Brown et al. 2013; Gensollen et al. 2016) or in host xenobiotic metabolism (Claus et al. 2011; Meinl et al. 2009; Nobutani et al. 2017). In light of well-established differences in treatment regimens and drug toxicity among male and female human subjects (Soldin and Mattison 2009), inclusion of both sexes in studies examining gut microbes is now encouraged by the National Institutes of Health and other funding agencies.

Finally, we observed a microbiome drift associated with aging, underscoring the importance of starting with murine cohorts at a similar age, as well as using age-matched control groups followed in parallel with test groups. Interestingly, female mice showed progressive changes in gut microbiota even after week 12 that was observed through week 24 of the study, while similar changes in males during this period were less apparent. Considering the ages of these mice at the time of analyses (19-22 weeks of age at week 12 and 31-34 weeks of age at week 24), we speculate that age-dependent shifts in female hormones could have contributed to the observed drift in gut microbiota (Org et al. 2016). Indeed, the pregnancy rate in C57Bl/6J female mice after 24 weeks of age is generally very low, possibly due to age-related hormonal changes that affect fertility. Diurnal variation in gut microbiota (Leone et al. 2015; Thaiss et al. 2014; Zarrinpar et al. 2014) underscores the importance of harvesting fecal samples at the same time in a day when repeat collections are required. Furthermore, a recent report suggested that the timing of the last cage change before sampling also may be a potential source for bias in murine microbiome studies (Rodriguez-Palacios et al. 2018). These factors should be taken in to consideration when a study is designed. To overcome this, we collected fecal samples at 6 am at 1 week after the cage change 
360

361

362

363

364

365

366

367

368

369

370

371

372

373

374

375

376

377

378

379

380

381

382

383

384

385

throughout the entire study period.

Further studies are necessary to refine and identify limitations to our outlined SOP. For instance, given the soiled bedding is exposed to oxygen there is a possibility that this SOP is skewed towards the successful transfer of aerobic bacteria rather than strict anaerobes. However, a similar bias may also occur in the co-housing procedure. Furthermore, with gavage procedure, the passing of microbes through the gastrointestinal (GI) tract itself could result in another selection bias in the lower GI tract. We believe that it is an important aspect to assess the limitations across all of these procedures in future studies.

\section{Conclusions}

Our bedding transfer SOP is practical and effective in reducing variability of fecal microbiota amongst individual mice when a large study cohort study is required. We also report that aging, sex, and time of fecal sampling are independent variables of microbial assemblage that should be taken into consideration when undertaking studies of this nature in mice. This SOP along with consideration of additional host drivers of the gut microbiota community membership and function may improve the quality of future murine studies of the gut microbiome.

\section{Acknowledgement}

We thank Mrinalini Rao, PhD for help in editing the manuscript. We also thank Masahiro Yamamoto, $\mathrm{PhD}$ for his support in the experiments. We appreciate the consulting program provided by Department of Statistics, The University of Chicago and thank Tae Kim and her team for their great help in statistical analyses.

\section{Reference}

Arantes-Rodrigues R, Henriques A, Pinto-Leite R, Faustino-Rocha A, Pinho-Oliveira J, TeixeiraGuedes C, Seixas F, Gama A, Colaco B, Colaco A, Oliveira PA (2012) The effects of repeated oral gavage on the health of male CD-1 mice. Lab Anim (NY) 41(5):129-34 doi:10.1038/laban0512-129

Brown EM, Sadarangani M, Finlay BB (2013) The role of the immune system in governing hostmicrobe interactions in the intestine. Nat Immunol 14(7):660-7 doi:10.1038/ni.2611

Caporaso JG, Kuczynski J, Stombaugh J, Bittinger K, Bushman FD, Costello EK, Fierer N, Pena 
391 AG, Goodrich JK, Gordon JI, Huttley GA, Kelley ST, Knights D, Koenig JE, Ley RE, Lozupone 392 CA, McDonald D, Muegge BD, Pirrung M, Reeder J, Sevinsky JR, Turnbaugh PJ, Walters WA, 393 Widmann J, Yatsunenko T, Zaneveld J, Knight R (2010) QIIME allows analysis of high394 throughput community sequencing data. Nat Methods 7(5):335-6 doi:10.1038/nmeth.f.303

395 Carding S, Verbeke K, Vipond DT, Corfe BM, Owen LJ (2015) Dysbiosis of the gut microbiota in disease. Microb Ecol Health Dis 26:26191 doi:10.3402/mehd.v26.26191

397 Choo JM, Trim PJ, Leong LEX, Abell GCJ, Brune C, Jeffries N, Wesselingh S, Dear TN, Snel MF, Rogers GB (2017) Inbred Mouse Populations Exhibit Intergenerational Changes in Intestinal Microbiota Composition and Function Following Introduction to a Facility. Front Microbiol 8:608 doi:10.3389/fmicb.2017.00608 Claus SP, Ellero SL, Berger B, Krause L, Bruttin A, Molina J, Paris A, Want EJ, de Waziers I, Cloarec O, Richards SE, Wang Y, Dumas ME, Ross A, Rezzi S, Kochhar S, Van Bladeren P, Lindon JC, Holmes E, Nicholson JK (2011) Colonization-induced host-gut microbial metabolic interaction. mBio 2(2):e0271-10 doi:10.1128/mBio.00271-10

David LA, Maurice CF, Carmody RN, Gootenberg DB, Button JE, Wolfe BE, Ling AV, Devlin AS, Varma Y, Fischbach MA, Biddinger SB, Dutton RJ, Turnbaugh PJ (2014) Diet rapidly and reproducibly alters the human gut microbiome. Nature 505(7484):559-63 doi:10.1038/nature12820

Devkota S, Wang Y, Musch MW, Leone V, Fehlner-Peach H, Nadimpalli A, Antonopoulos DA, Jabri B, Chang EB (2012) Dietary-fat-induced taurocholic acid promotes pathobiont expansion and colitis in Il10-/- mice. Nature 487(7405):104-8 doi:10.1038/nature11225

Microbiome

Project (2016) 16S Illumina

Amplicon Protocol. http://www.earthmicrobiome.org/protocols-and-standards/16s/. Accessed 27 Feburary 2017 Ericsson AC, Davis JW, Spollen W, Bivens N, Givan S, Hagan CE, McIntosh M, Franklin CL (2015) Effects of vendor and genetic background on the composition of the fecal microbiota of inbred mice. PLoS One 10(2):e0116704 doi:10.1371/journal.pone.0116704

417 Faith JJ, Guruge JL, Charbonneau M, Subramanian S, Seedorf H, Goodman AL, Clemente JC, 418 Knight R, Heath AC, Leibel RL, Rosenbaum M, Gordon JI (2013) The long-term stability of the 419 human gut microbiota. Science 341(6141):1237439 doi:10.1126/science.1237439

420 Gensollen T, Iyer SS, Kasper DL, Blumberg RS (2016) How colonization by microbiota in early 421 life shapes the immune system. Science 352(6285):539-44 doi:10.1126/science.aad9378 
422 Haro C, Rangel-Zuniga OA, Alcala-Diaz JF, Gomez-Delgado F, Perez-Martinez P, Delgado-Lista 423 J, Quintana-Navarro GM, Landa BB, Navas-Cortes JA, Tena-Sempere M, Clemente JC, Lopez424 Miranda J, Perez-Jimenez F, Camargo A (2016) Intestinal Microbiota Is Influenced by Gender and 425 Body Mass Index. PLoS One 11(5):e0154090 doi:10.1371/journal.pone.0154090

426 Hildebrand F, Nguyen TL, Brinkman B, Yunta RG, Cauwe B, Vandenabeele P, Liston A, Rases J 427 (2013) Inflammation-associated enterotypes, host genotype, cage and inter-individual effects drive 428 gut microbiota variation in common laboratory mice. Genome Biol. 14(1):R4 doi: 10.1186/gb429 2013-14-1-r4.

430 Hoy YE, Bik EM, Lawley TD, Holmes SP, Monack DM, Theriot JA, Relman DA (2015) Variation 431 in Taxonomic Composition of the Fecal Microbiota in an Inbred Mouse Strain across Individuals 432 and Time. PLoS One 10(11):e0142825 doi:10.1371/journal.pone.0142825

433 Hufeldt MR, Nielsen DS, Vogensen FK, Midtvedt T, Hansen AK (2010) Variation in the gut 434 microbiota of laboratory mice is related to both genetic and environmental factors. Comp Med $43560(5): 336-47$

436 Ivanov, II, Frutos Rde L, Manel N, Yoshinaga K, Rifkin DB, Sartor RB, Finlay BB, Littman DR 437 (2008) Specific microbiota direct the differentiation of IL-17-producing T-helper cells in the 438 mucosa of the small intestine. Cell Host Microbe 4(4):337-49 doi:10.1016/j.chom.2008.09.009

439 Kashtanova DA, Popenko AS, Tkacheva ON, Tyakht AB, Alexeev DG, Boytsov SA (2016) 440 Association between the gut microbiota and diet: Fetal life, early childhood, and further life. 441 Nutrition 32(6):620-7 doi:10.1016/j.nut.2015.12.037

442 Langille MG, Meehan CJ, Koenig JE, Dhanani AS, Rose RA, Howlett SE, Beiko RG (2014) 443 Microbial shifts in the aging mouse gut. Microbiome 2(1):50 doi:10.1186/s40168-014-0050-9

444 Leone V, Gibbons SM, Martinez K, Hutchison AL, Huang EY, Cham CM, Pierre JF, Heneghan 445 AF, Nadimpalli A, Hubert N, Zale E, Wang Y, Huang Y, Theriault B, Dinner AR, Musch MW, 446 Kudsk KA, Prendergast BJ, Gilbert JA, Chang EB (2015) Effects of diurnal variation of gut 447 microbes and high-fat feeding on host circadian clock function and metabolism. Cell Host Microbe 448 17(5):681-9 doi:10.1016/j.chom.2015.03.006

449 Liu T, Hougen H, Vollmer AC, Hiebert SM (2012) Gut bacteria profiles of Mus musculus at the 450 phylum and family levels are influenced by saturation of dietary fatty acids. Anaerobe 18(3):3314517 doi:10.1016/j.anaerobe.2012.02.004

452 Lozupone CA, Stombaugh JI, Gordon JI, Jansson JK, Knight R (2012) Diversity, stability and 
453 resilience of the human gut microbiota. Nature 489(7415):220-30 doi:10.1038/nature11550

454 Markle JG, Frank DN, Mortin-Toth S, Robertson CE, Feazel LM, Rolle-Kampczyk U, von Bergen 455 M, McCoy KD, Macpherson AJ, Danska JS (2013) Sex differences in the gut microbiome drive 456 hormone-dependent regulation of autoimmunity. Science 339(6123):1084-8 457 doi:10.1126/science. 1233521

458 McCafferty J, Muhlbauer M, Gharaibeh RZ, Arthur JC, Perez-Chanona E, Sha W, Jobin C, Fodor 459 AA (2013) Stochastic changes over time and not founder effects drive cage effects in microbial 460 community assembly in a mouse model. ISME J 7(11):2116-25 doi:10.1038/ismej.2013.106

461 Meinl W, Sczesny S, Brigelius-Flohe R, Blaut M, Glatt H (2009) Impact of gut microbiota on 462 intestinal and hepatic levels of phase 2 xenobiotic-metabolizing enzymes in the rat. Drug Metab 463 Dispos 37(6):1179-86 doi:10.1124/dmd.108.025916

464 Moon C, Baldridge MT, Wallace MA, Burnham CA, Virgin HW, Stappenbeck TS (2015) 465 Vertically transmitted faecal IgA levels determine extra-chromosomal phenotypic variation. 466 Nature 521(7550):90-3 doi:10.1038/nature14139

467 Moore RJ, Stanley D (2016) Experimental design considerations in microbiota/inflammation 468 studies. Clin Transl Immunology 5(7):e92 doi:10.1038/cti.2016.41

469 Murphy EF, Cotter PD, Healy S, Marques TM, O'Sullivan O, Fouhy F, Clarke SF, O'Toole PW, 470 Quigley EM, Stanton C, Ross PR, O'Doherty RM, Shanahan F (2010) Composition and energy 471 harvesting capacity of the gut microbiota: relationship to diet, obesity and time in mouse models. 472 Gut 59(12):1635-42 doi:10.1136/gut.2010.215665

473 National Institues of Health's Central Resources for Grants and Funding Information. Rigor and 474 Reproducibility. PUblisher. https://grants.nih.gov/reproducibility/index.htm. Accessed 23 October $475 \quad 2017$

476 Nobutani K, Miyoshi J, Musch MW, Nishiyama M, Watanabe J, Kaneko A, Yamamoto M, 477 Yoshida M, Kono T, Jeong H, Chang EB (2017) Daikenchuto (TU-100) alters murine hepatic and 478 intestinal drug metabolizing enzymes in an in vivo dietary model: effects of gender and 479 withdrawal. Pharmacol Res Perspect 5(5) doi:10.1002/prp2.361

480 O'Toole PW, Jeffery IB (2015) Gut microbiota and aging. Science 350(6265):1214-5 481 doi:10.1126/science.aac8469

482 Org E, Mehrabian M, Parks BW, Shipkova P, Liu X, Drake TA, Lusis AJ (2016) Sex differences 483 and hormonal effects on gut microbiota composition in mice. Gut Microbes 7(4):313-322 
484

485

486

487

488

489

490

491

492

493

494

495

496

497

498

499

500

501

502

503

504

505

506

507

508

509

510

511

512 $513 \quad 2017$

514 Turnbaugh PJ, Hamady M, Yatsunenko T, Cantarel BL, Duncan A, Ley RE, Sogin ML, Jones WJ,

doi:10.1080/19490976.2016.1203502

Org E, Parks BW, Joo JW, Emert B, Schwartzman W, Kang EY, Mehrabian M, Pan C, Knight R, Gunsalus R, Drake TA, Eskin E, Lusis AJ (2015) Genetic and environmental control of host-gut microbiota interactions. Genome Res 25(10):1558-69 doi:10.1101/gr.194118.115

Rodriguez-Palacios A, Aladyshkina N, Ezeji JC, Erkkila HL, Conger M, Ward J, Webster J, Cominelli F (2018) 'Cyclical Bias' in Microbiome Research Revealed by A Portable Germ-Free Housing System Using Nested Isolation. Sci Rep. 8(1):3801 doi: 10.1038/s41598-018-20742-1.

Rogers GB, Kozlowska J, Keeble J, Metcalfe K, Fao M, Dowd SE, Mason AJ, McGuckin MA, Bruce KD (2014) Functional divergence in gastrointestinal microbiota in physically-separated genetically identical mice. Sci Rep 4:5437 doi:10.1038/srep05437

Saraswati S, Sitaraman R (2014) Aging and the human gut microbiota-from correlation to causality. Front Microbiol 5:764 doi:10.3389/fmicb.2014.00764

Schloss PD, Schubert AM, Zackular JP, Iverson KD, Young VB, Petrosino JF (2012) Stabilization of the murine gut microbiome following weaning. Gut Microbes 3(4):383-93 doi:10.4161/gmic. 21008

Schloss PD, Westcott SL (2011) Assessing and improving methods used in operational taxonomic unit-based approaches for $16 \mathrm{~S}$ rRNA gene sequence analysis. Appl Environ Microbiol 77(10):3219-26 doi:10.1128/AEM.02810-10

Shreiner AB, Kao JY, Young VB (2015) The gut microbiome in health and in disease. Curr Opin Gastroenterol 31(1):69-75 doi:10.1097/MOG.0000000000000139

Soldin OP, Mattison DR (2009) Sex differences in pharmacokinetics and pharmacodynamics. Clin Pharmacokinet 48(3):143-57 doi:10.2165/00003088-200948030-00001

Thaiss CA, Zeevi D, Levy M, Zilberman-Schapira G, Suez J, Tengeler AC, Abramson L, Katz MN, Korem T, Zmora N, Kuperman Y, Biton I, Gilad S, Harmelin A, Shapiro H, Halpern Z, Segal E, Elinav E (2014) Transkingdom control of microbiota diurnal oscillations promotes metabolic homeostasis. Cell 159(3):514-29 doi:10.1016/j.cell.2014.09.048

The American Institute of Nutrition (1977) Report of the American Institute of Nurtition ad hoc Committee on Standards for Nutritional Studies. J Nutr 107(7):1340-8

The GreenGenes Database (2013). http://greengenes.secondgenome.com. Accessed 27 Feburary 
515 Roe BA, Affourtit JP, Egholm M, Henrissat B, Heath AC, Knight R, Gordon JI (2009a) A core 516 gut microbiome in obese and lean twins. Nature 457(7228):480-4 doi:10.1038/nature07540

517 Turnbaugh PJ, Ridaura VK, Faith JJ, Rey FE, Knight R, Gordon JI (2009b) The effect of diet on 518 the human gut microbiome: a metagenomic analysis in humanized gnotobiotic mice. Sci Transl 519 Med 1(6):6ra14 doi:10.1126/scitranslmed.3000322

520 Wang Y, Hoenig JD, Malin KJ, Qamar S, Petrof EO, Sun J, Antonopoulos DA, Chang EB, Claud 521 EC (2009) 16S rRNA gene-based analysis of fecal microbiota from preterm infants with and 522 without necrotizing enterocolitis. ISME J 3(8):944-54 doi:10.1038/ismej.2009.37

523 Wu GD, Chen J, Hoffmann C, Bittinger K, Chen YY, Keilbaugh SA, Bewtra M, Knights D, 524 Walters WA, Knight R, Sinha R, Gilroy E, Gupta K, Baldassano R, Nessel L, Li H, Bushman FD, 525 Lewis JD (2011) Linking long-term dietary patterns with gut microbial enterotypes. Science 526 334(6052):105-8 doi:10.1126/science.1208344

527 Yatsunenko T, Rey FE, Manary MJ, Trehan I, Dominguez-Bello MG, Contreras M, Magris M, 528 Hidalgo G, Baldassano RN, Anokhin AP, Heath AC, Warner B, Reeder J, Kuczynski J, Caporaso 529 JG, Lozupone CA, Lauber C, Clemente JC, Knights D, Knight R, Gordon JI (2012) Human gut 530 microbiome viewed across age and geography. Nature 486(7402):222-7 doi:10.1038/nature11053 531 Zarrinpar A, Chaix A, Yooseph S, Panda S (2014) Diet and feeding pattern affect the diurnal 532 dynamics of the gut microbiome. Cell Metab 20(6):1006-17 doi:10.1016/j.cmet.2014.11.008 


\section{Figure 1}

Murine cohort design

All mice in cohorts 1-3 were on a C57BI/6J background, maintained on corncob bedding under standard housing conditions and fed Teklad Global 18\% Protein Rodent Diet unless indicated otherwise. (A) Cohort 1 - Five breeding pairs were prepared from mice housed in one room ( $F_{0}$ generation). 25 breeding pairs were set up from the $F_{0}$ progeny $\left(F_{1}\right.$ generation). Fiftyseven female and 57 male mice of $F_{2}$ generation were used for analysis of cohort 1 . Bedding was mixed among all $F_{2}$ cages in cohort 1 beginning at weaning ( 3 weeks old) until the diet switch to AIN-76A (6-12 weeks old). All mice were housed in one room. (B) Cohort 2 - Twelve and 7 age-matched male mice (19 total, 10-12 weeks old) were obtained from 2 separate C57BI/6 breeding colonies, respectively which were housed in a single, yet separate room than cohort 1. (C) Cohort 3 - Thirty-six age-matched male mice ( 8 - 10 weeks old) were purchased from the Jackson Laboratories and acclimated for 2 weeks in a single, yet separate room than both cohorts 1 and 2 . 


\section{A Cohort 1}

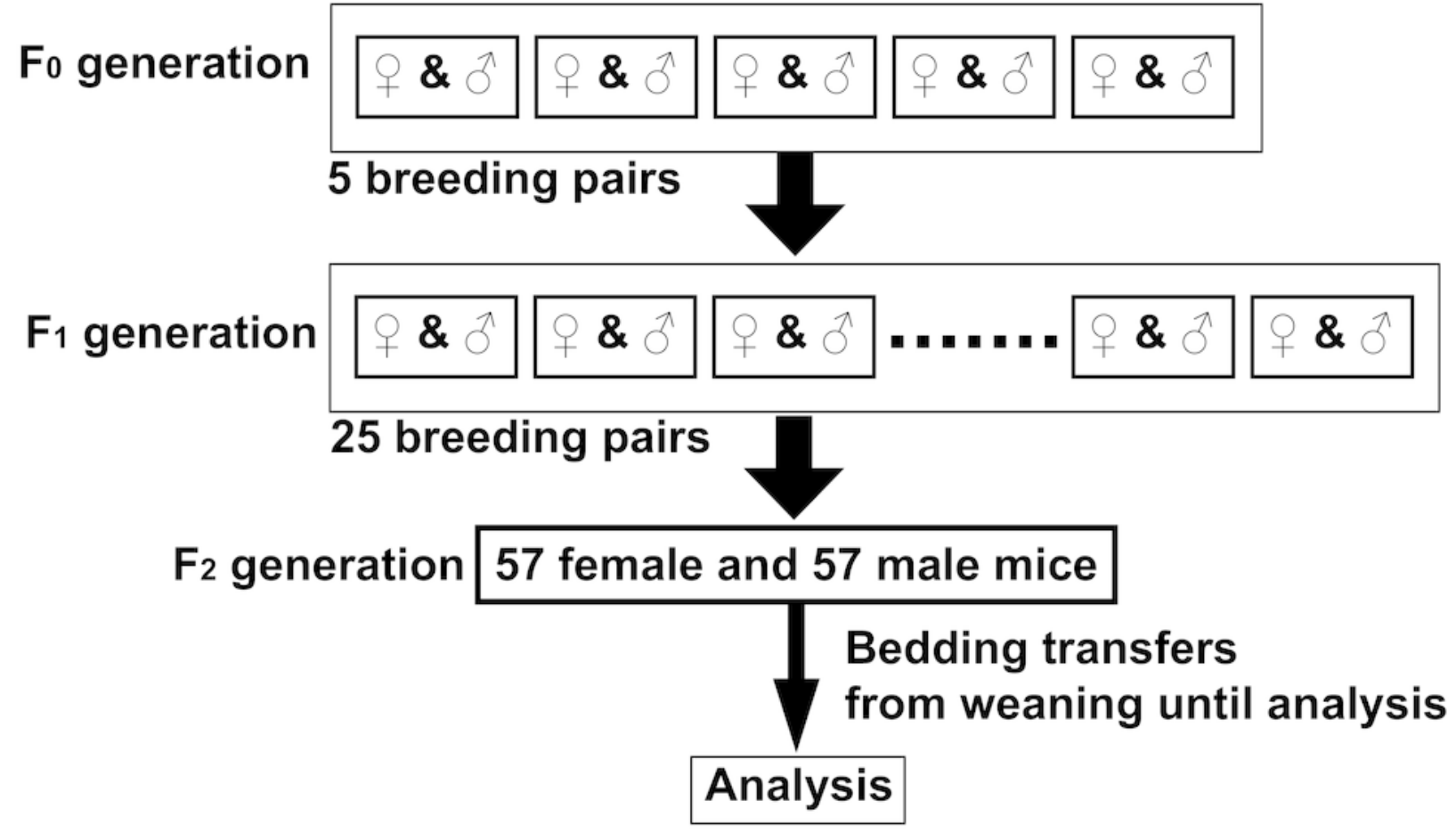

B Cohort 2

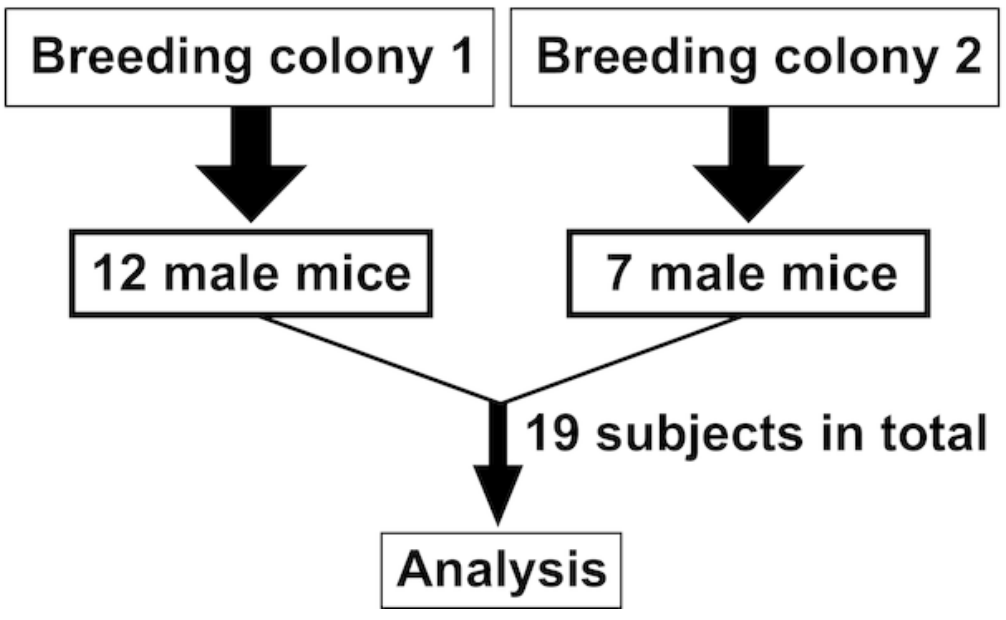

C Cohort 3

36 male mice

Acclimation for 2 weeks 


\section{Figure 2}

Mixed bedding transfer reduces the variability of fecal microbiota among mice

(A) PCoA plots of both unweighted and weighted UniFrac distances of 165 rRNA amplicon sequences from fecal samples obtained from cohort 1 males (red squares) and those of cohort 2 males (blue circles). (B) The unweighted and weighted UniFrac distances between samples within cohort 1 and those within cohort 2 were compared. (C) PCoA plots of both unweighted and weighted UniFrac distances for samples of cohort 1 (red squares) and those of cohort 3 (blue circles). (D) The unweighted and weighted UniFrac distances between samples within cohort 1 and those within cohort 3 were compared. $* * * * p=0.0001$. 
A
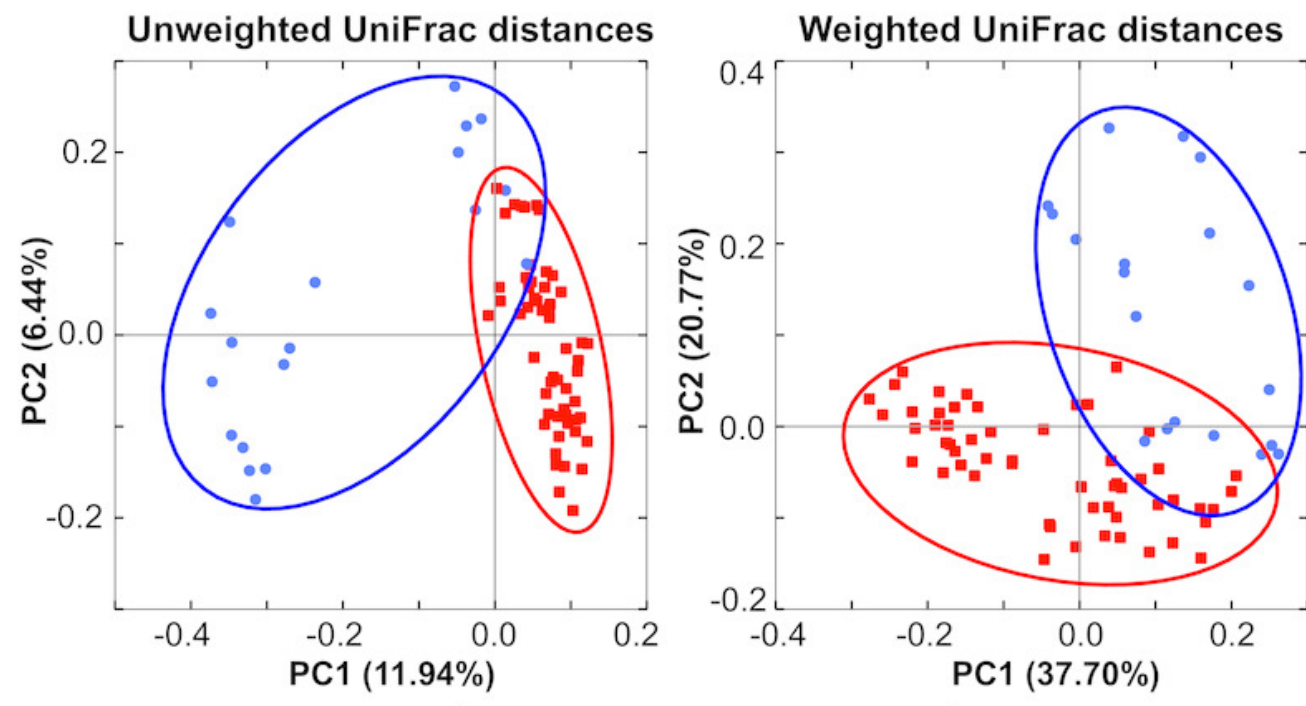

Cohort 1

C

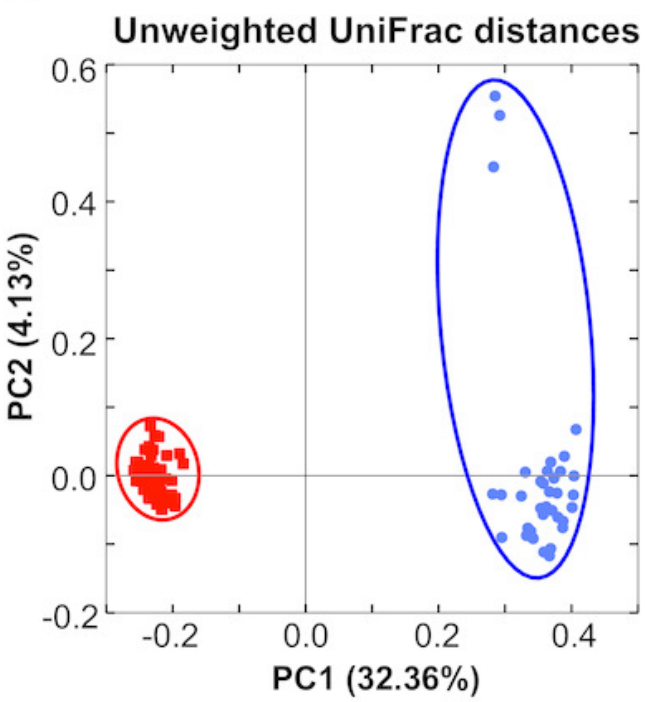

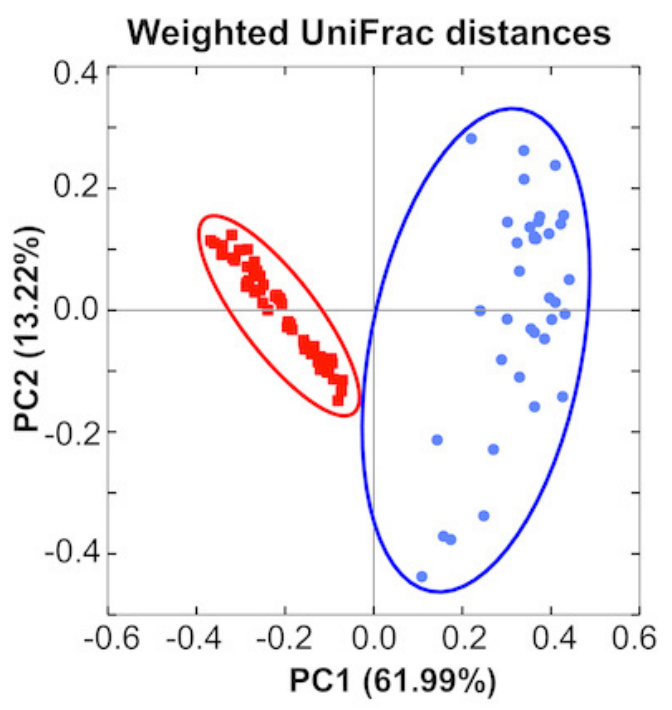

B

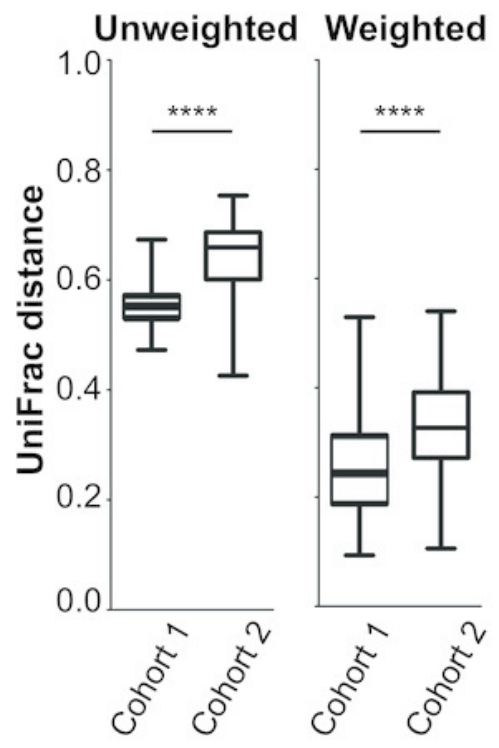

D

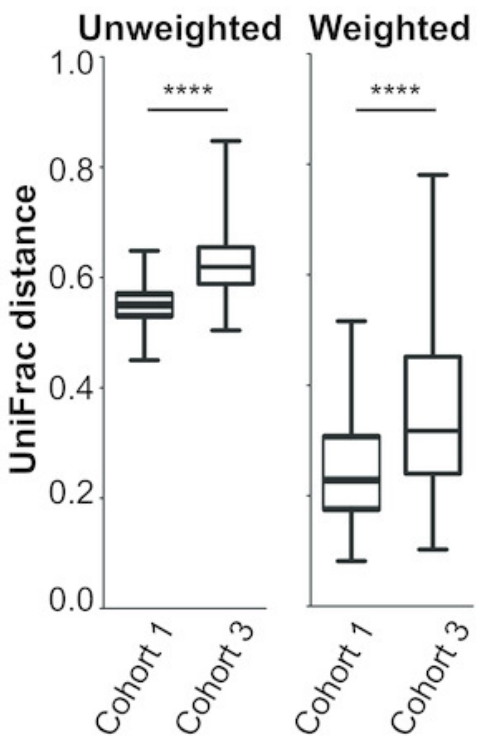


Figure 3

Dietary switch results in a shift of the fecal microbiota composition

Comparison of the fecal microbiota of 57 female mice (A) and 57 male mice (B) in cohort 1 when fed Teklad Global 18\% Protein Rodent Diet (red circles) and the same mice at 1 week after switching the diet to AIN-76A Purified Diet (blue squares). PCoA plots of unweighted and weighted UniFrac distances are shown.

A

Female
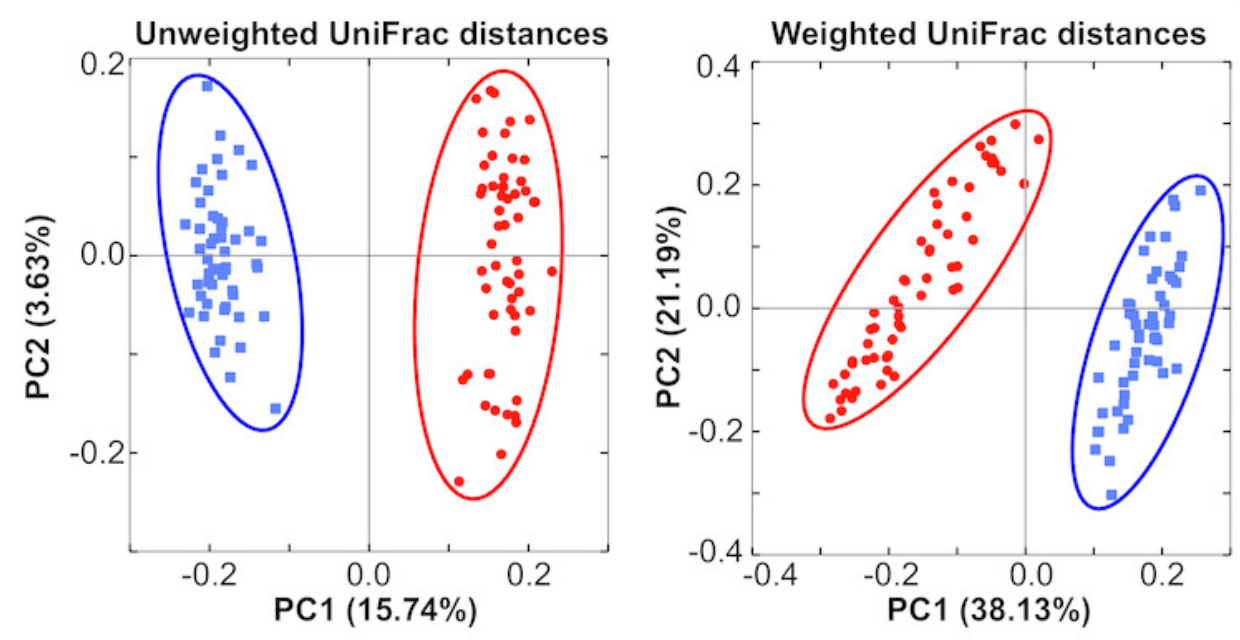

\begin{tabular}{c|c|c|}
\multicolumn{4}{c}{} & $\begin{array}{c}\text { ADONIS } \\
\text { (Diet switch) }\end{array}$ \\
\cline { 2 - 3 } \multicolumn{1}{c|}{} & Unweighted & Weighted \\
\hline $\boldsymbol{p}$ value & 0.0001 & 0.0001 \\
\hline $\mathbf{R}^{2}$ & 0.157 & 0.405 \\
\hline
\end{tabular}

B

Male
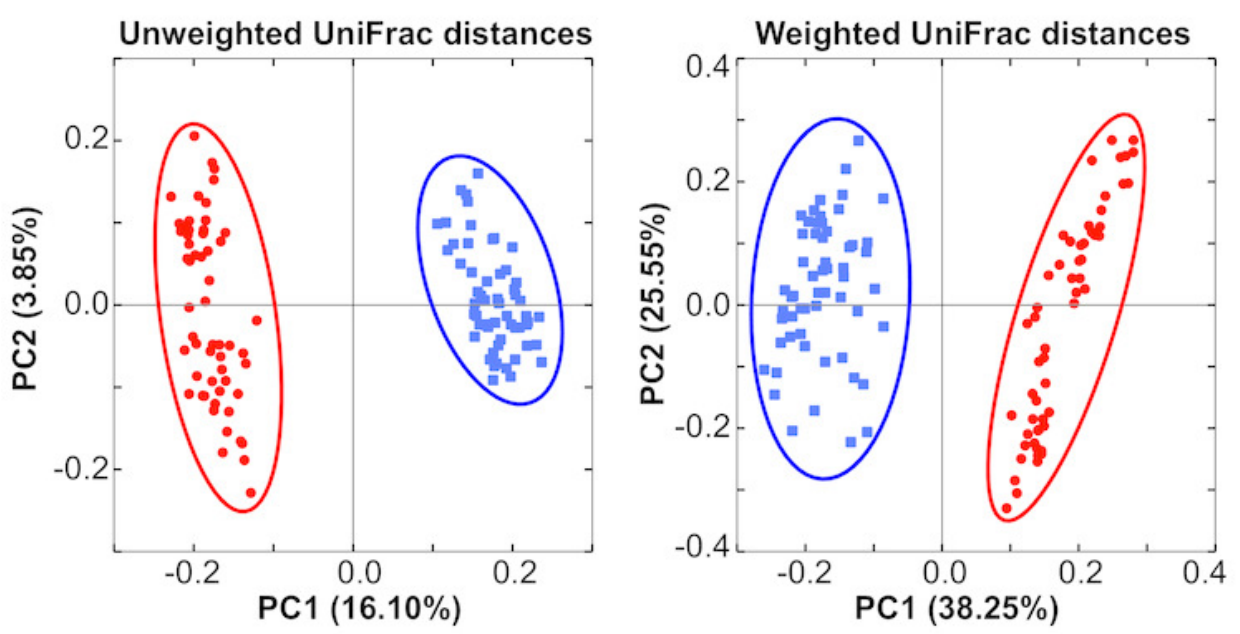

\begin{tabular}{|c|c|c|}
\hline \multicolumn{3}{|c|}{$\begin{array}{l}\text { ADONIS } \\
\text { (Diet switch) }\end{array}$} \\
\hline & Unweighted & Weighted \\
\hline$p$ value & 0.0001 & 0.0001 \\
\hline $\mathbf{R}^{2}$ & 0.158 & 0.399 \\
\hline
\end{tabular}




\section{Figure 4}

Sex drives gut microbial assemblage independently of mixed bedding transfer that persists over time

Fecal microbiota of 8 female and 8 male mice (7-10 weeks old) was tracked over time for 24 weeks. Unweighted and weighted UniFrac distances were analyzed at weeks 0,12 and 24 to compare female and male samples. PCoA plots present female (red circles) and male (blue squares) samples at week 0 (A), week 12 (B) and week 24 (C). 
A

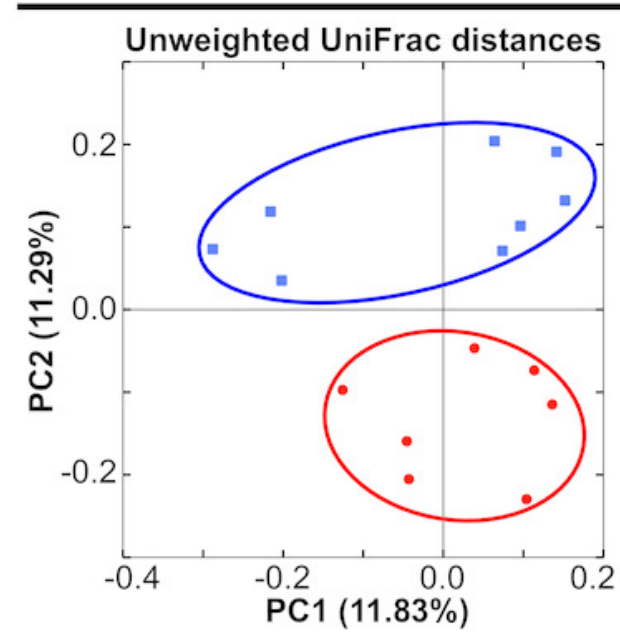

Week 0

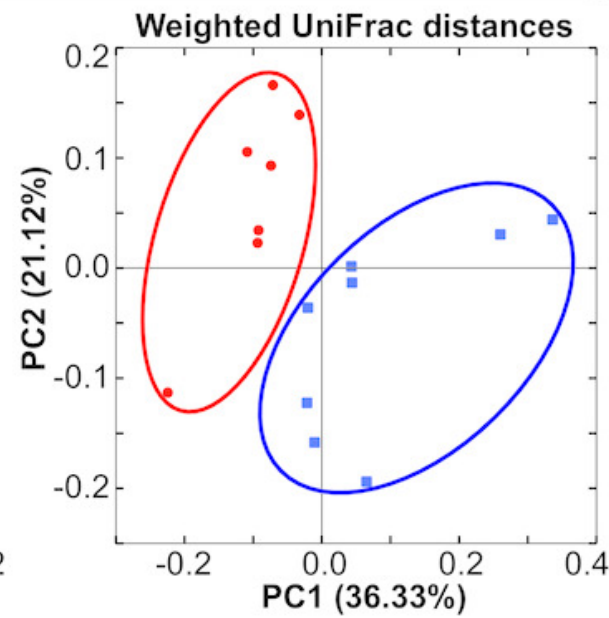

Week 12
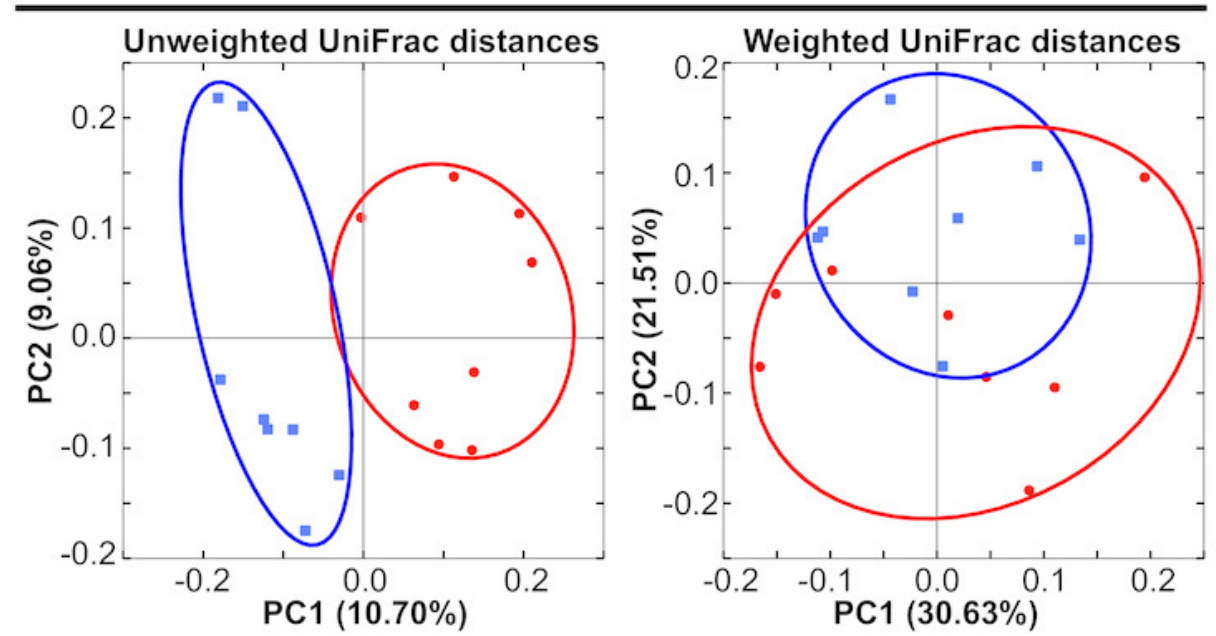

C

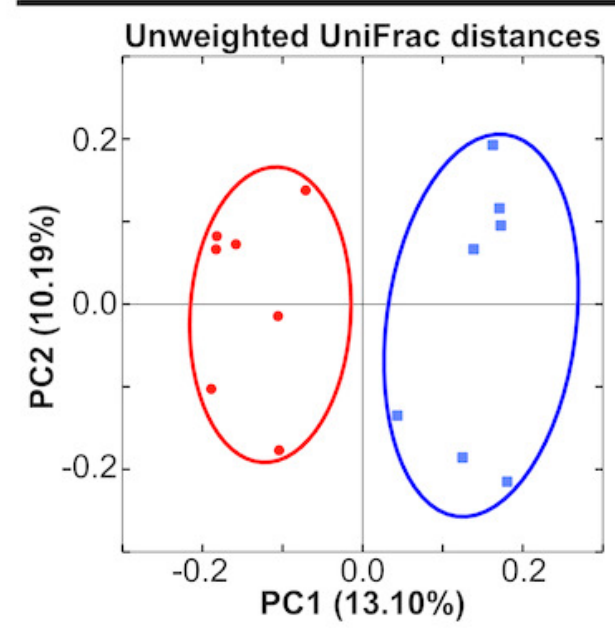

Week 24

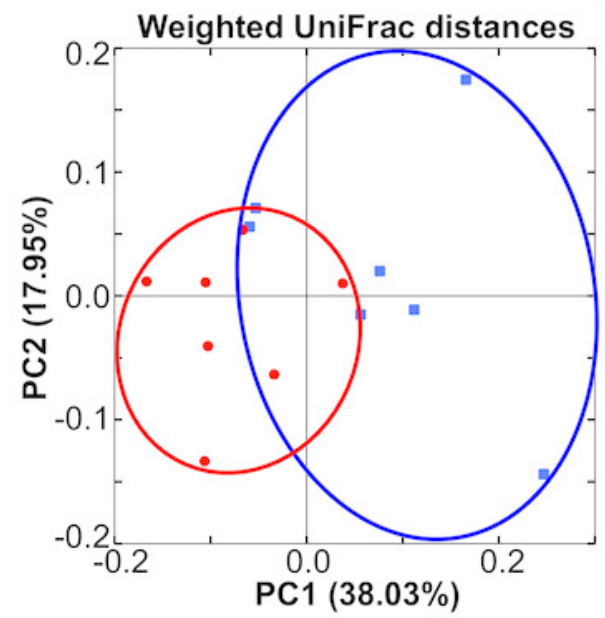

Analysis of Similarities (Female vs. Male)

\begin{tabular}{|c|c|c|}
\cline { 2 - 3 } \multicolumn{1}{c|}{} & Unweighted & Weighted \\
\hline $\boldsymbol{p}$ value & 0.001 & 0.001 \\
\hline $\mathbf{R}$ & 0.432 & 0.397 \\
\hline
\end{tabular}

Analysis of Similarities (Female vs. Male)

\begin{tabular}{|c|c|c|}
\cline { 2 - 3 } \multicolumn{1}{c|}{} & Unweighted & Weighted \\
\hline $\boldsymbol{p}$ value & 0.001 & 0.004 \\
\hline $\mathbf{R}$ & 0.465 & 0.277 \\
\hline
\end{tabular}

Analysis of Similarities (Female vs. Male)

\begin{tabular}{|c|c|c|}
\cline { 2 - 3 } \multicolumn{1}{c|}{} & Unweighted & Weighted \\
\hline $\boldsymbol{p}$ value & 0.003 & 0.008 \\
\hline $\mathbf{R}$ & 0.695 & 0.319 \\
\hline
\end{tabular}

Female mouse

Male mouse 


\section{Figure 5}

Aging is an independent driver of microbial assemblage, particularly in female mice

( $A$ and $B$ ) PCoA plots of unweighted and weighted UniFrac distances of fecal microbiota at weeks 0 (red squares), 12 (blue triangles) and 24 (orange circles) in each gender. (C and D) PCoA plots with a time axis in each gender are shown.

A

Female

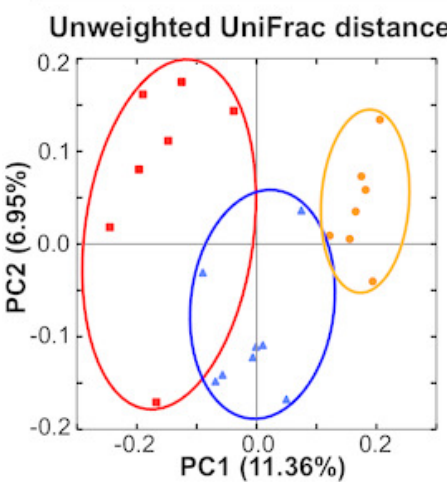

Week 0

Week 12

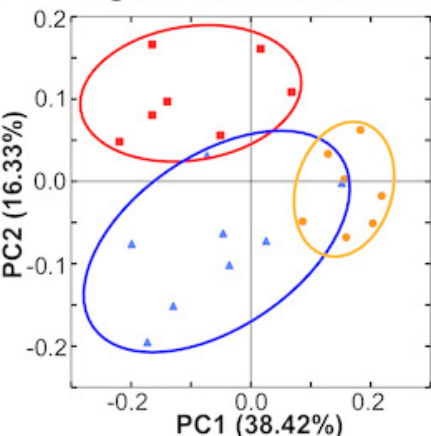

C

Female

Unweighted UniFrac distances

Weighted UniFrac distances
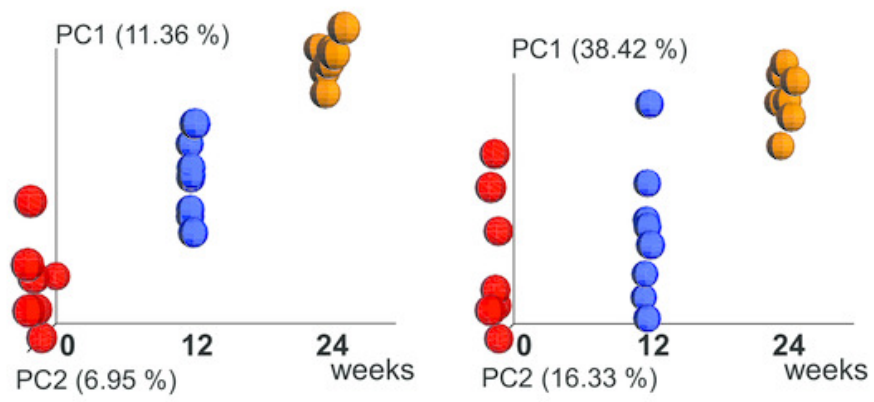

ADONIS

\begin{tabular}{|c|c|c|}
\cline { 2 - 3 } \multicolumn{1}{c|}{$($ Weeks) } & Unweighted & Weighted \\
\hline $\boldsymbol{p}$ value & 0.0001 & 0.0001 \\
\hline $\mathbf{R}^{2}$ & 0.189 & 0.362 \\
\hline
\end{tabular}

B

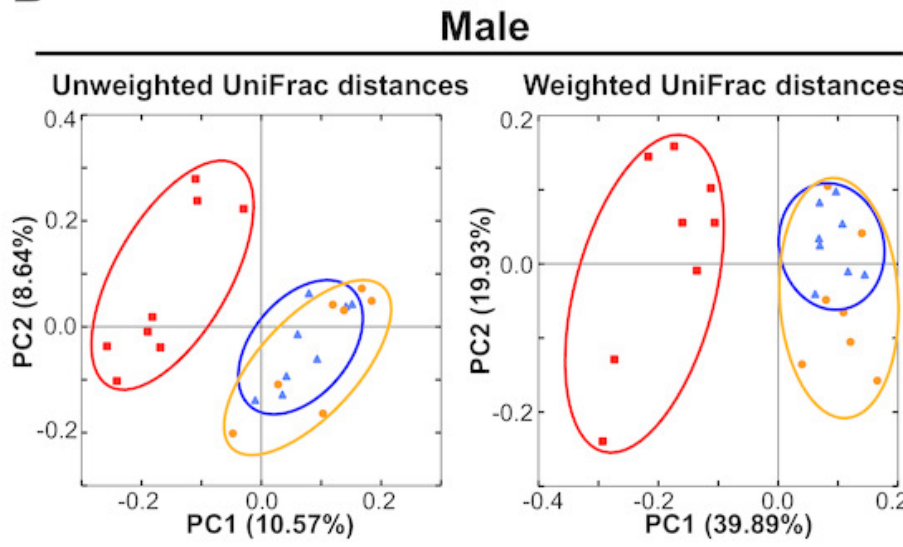

Week 0

Week $12 \bigcirc$ Week 24

D

Male

Unweighted UniFrac distances Weighted UniFrac distances
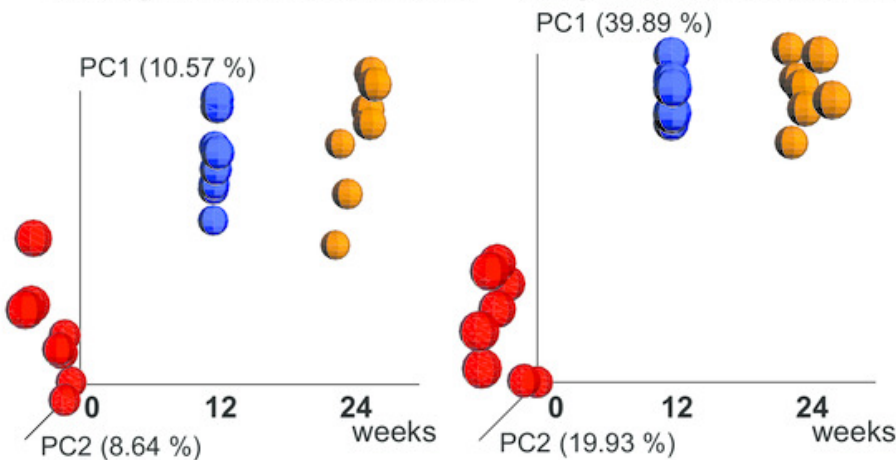

\begin{tabular}{|c|c|c|}
\hline \multirow{2}{*}{$\begin{array}{l}\text { ADONIS } \\
\text { (Weeks) }\end{array}$} & & \\
\hline & Unweighted & Weighted \\
\hline$p$ value & 0.001 & 0.0004 \\
\hline $\mathbf{R}^{2}$ & 0.142 & 0.396 \\
\hline
\end{tabular}

